for being too slap happy, it may be that accurate completion of a diary is an unreasonable expectation of patients, who like all humans, are prone to forget. It would make sense to design studies that accommodate human forgetfulness and error and, in particular, to provide instructions that tell the patient what to do when a day is missed. Coupled with such instructions, electronic, time coded diaries could provide a better method for ensuring the quality of diary records.
We thank Ms Jo Hollands of Allen \& Hanbury's for providing the Psion Organisers used in the study.

1 Baddeley A. Human memory: theory and practice. London: Erlbaum, 1990.

2 Watson D. Intraindividual and interdividual analysis of positive and negative affect: their relation to health complaints, perceived stress, and dail activities. I Pers Soc Psychol 1988;54:1020-30.

3 Spielberger CD. Manual for the state-trait anxiety inventory. Palo Alto, California: Consulting Psychologists Press, 1983.

(Accepted 22 December 1992)

\title{
Diagnosis and management after life threatening events in infants and young children who received cardiopulmonary resuscitation
}

\author{
Martin P Samuels, Christian F Poets, Jane P Noyes, Hans Hartmann, John Hewertson, \\ David P Southall
}

\begin{abstract}
Objective-To determine the mechanisms and thereby appropriate management for apparent life threatening events treated with cardiopulmonary resuscitation in infants and young children.

Design-Prospective clinical and physiological study.

Setting-Royal Brompton Hospital or in patients' homes, or both.

Subjects-157 Patients referred at median age $2 \cdot 8$ months (range 1 week to 96 months), 111 (71\%) had recurrent events, 44 were born preterm, 19 were siblings of infants who had died suddenly and unexpectedly, and 18 were over 12 months old.

Interventions-Multichannel physiological recordings, including oxygenation, in hospital $(n=150)$ and at home $(n=61)$. Additional recordings with electroencephalogram, video, or other respiratory measures were used to confirm diagnoses. Management involved monitoring of oxygen at home, additional inspired oxygen, anticonvulsant treatment, or child protection procedures.
\end{abstract}

Main outcome measures-Abnormalities on recordings compared to published normal data and their correlation with clinical events; sudden death.

Results -53 of 150 patients had abnormalities of oxygenation on hospital recordings, 28 of whom had an accompanying clinical event. Home recordings produced physiological data from 34 of 61 patients during subsequent clinical events. Final diagnoses were reached in 77 patients: deliberate suffocation by a parent (18), hypoxaemia induced by epileptic seizure (10), fabricated history and data (Munchausen syndrome by proxy; seven), acute hypoxaemia of probable respiratory origin (40), and changes in peripheral perfusion and skin colour without hypoxaemia (two). Four patients died: three suddenly and unexpectedly (none on home oxygen monitors) and one from pneumonia.

Conclusions-Identification of mechanisms is essential to the appropriate management of infants with apparent life threatening events.

\section{Introduction}

An apparent life threatening event has been defined as "an episode that is frightening to the observer and that is characterised by some combination of apnea (central or occasionally obstructive), color change (usually cyanotic or pallid), marked change in muscle tone, choking, or gagging".' When mouth to mouth resuscitation is needed there is a particularly high risk of subsequent sudden death. In one survey 10 of 76 patients with such events died. ${ }^{2}$ We have used physiological recordings in hospital and at home to identify mechanisms for these events and report our findings in a subgroup that received mouth to mouth resuscitation.

\section{Patients and methods}

Over 44 months 157 patients ( 96 boys) who had suffered one or more events out of hospital and received mouth to mouth resuscitation were referred for clinical management to our department at the Royal Brompton Hospital. One hundred and thirteen had been born at term and the others at a median gestational age of 32 weeks (range 24-36); none of the latter had been discharged from their neonatal unit on additional inspired oxygen. Median postnatal age at referral was $2 \cdot 8$ months (range 1 week to 96 months); 128 were 6 months and under and 18 were over 12 months of age. Forty six patients had a single event, 59 had two-five, 21 had six-10, and 31 had more than 10 events before referral.

Conditions considered as triggers for events, such as infections, anaemia, and biochemical disturbances, were excluded or treated. In some cases electroencephalography (EEG), standard electrocardiography, 24 hour electrocardiography, barium swallow, or oesophageal $\mathrm{pH}$ studies were undertaken but failed to identify abnormalities considered relevant to the events. In 19 a previous sibling had died suddenly and unexpectedly. In nine patients suffocation was suspected at referral.

\section{PHYSIOLOGICAL RECORDINGS IN HOSPITAL}

Long term (8 hours to 3 weeks) analogue tape recordings of arterial oxygen saturation $\left(\mathrm{SaO}_{2}\right)$ (Nellcor $\mathrm{N}-200$ modified to provide beat to beat data), the plethysmographic (pulse) waveforms (to validate $\mathrm{SaO}_{2}$ ), breathing movements (Graseby capsule), electrocardiograms, and skin (transcutaneous) $\mathrm{po}_{2}$ with the sensor heated to $43^{\circ} \mathrm{C}$ (Kontron 821S) were performed on 150 patients. ${ }^{3}$ Recordings were printed on an ink jet chart recorder (Siemens Mingograf) at $3.1 \mathrm{~mm}$ per second.

Seven did not undergo recordings. Reasons were suspected deliberate suffocation (by a parent) in two, a single event in two older children (13 and 48 months), and lack of inpatient facilities in three. In one of the latter, death occurred after referral but before admission.

PHYSIOLOGICAL RECORDINGS AT HOME

Thirty nine patients with recurrent events but normal recordings in hospital, 20 with abnormal 
recordings in hospital but no captured clinical events, and two who did not undergo hospital recordings underwent oxygen event recordings (Research Monitoring Systems, or Kontron) at home. ${ }^{4}$ Date, time, $\mathrm{SaO}_{2}$, plethysmographic waveforms, skin $\mathrm{po}_{2}$, breathing movements, and electrocardiograms were continuously monitored and recorded on to a $128 \mathrm{kB}$ digital memory card $(86 \times 54 \times 3 \mathrm{~mm})$, which was continually updated with the last $20-30$ minutes of data. In addition a log of use of the event recorder was stored. Skin $\mathrm{po}_{2}$ was the only variable to register an alarm, thereby identifying sudden hypoxaemic episodes to the parent. ${ }^{5}$ After an event the memory card was transferred for analysis.

\section{ANALYSIS OF DATA}

Baseline $\mathrm{SaO}_{2}$ was considered abnormally low if the value assessed from the recording was $<95 \%$ (based on data from healthy term and preterm infants. ${ }^{\circ}$ ). Abnormal hypoxaemic episodes were considered present if more than three desaturations to $\leqslant 80 \%$ for $\geqslant 4$ seconds with apnoeic pauses occurred in a 12 hour hospital recording (95th percentile in healthy infants ${ }^{67}$ ) or if there was any desaturation to $\leqslant 80 \%$ for $\geqslant 4$ seconds which was unassociated with an apnoeic pause - that is, when the onset of desaturation began $>12$ seconds after the onset of any pause. ${ }^{67}$ Patterns of breathing and electrocardiograms were also examined.

If an event occurred a detailed clinical history was taken, including the time, state (awake or asleep), person(s) present at onset, the observed clinical signs, and the time at which the skin $\mathrm{po}_{2}$ value resulted in an alarm. These data were correlated with the signals and log of time on the recording.

The following patterns, and thereby potential mechanisms, were observed. (1) Falls in skin $\mathrm{po}_{2}$ but without falls in $\mathrm{SaO}_{2}$, apnoeic pauses, or cardiac arrhythmia (considered to represent changes in skin perfusion). (2) Falls in skin $\mathrm{po}_{2}$ and $\mathrm{SaO}_{2}$ associated with an attenuation, irregularity, or absence of breathing movements with tachycardia or bradycardia (considered to be true hypoxaemia suggestive of a natural, primary respiratory mechanism ${ }^{8}$ or of an epileptic seizure). (3) Falls in skin $\mathrm{po}_{2}$ and $\mathrm{SaO}_{2}$ with or without bradycardia, preceded by the sudden onset and continued presence (for 40-80 seconds) of a large increase in amplitude and irregularity of the breathing movement signal. For the first 40-80 seconds of these signals there were sinus tachycardia and artefact on the electrocardiograms or plethysmograph signals, suggesting large body movements. This pattern, when accompanied by false or varying descriptions of the time or sleep state of the patient, was considered suggestive of suffocation (see below). (4) Changes in signals that were inconsistent with parental history or with a natural pathophysiology. These included parental reports of apnoea during sleep with recordings showing a breathing pattern characteristic of the awake state; a reported prolonged pause in breathing but an electronically straight line on the breathing movement signal unaccompanied by any changes in heart rate or $\mathrm{SaO}_{2}$ levels and with a persisting respiratory sinus arrhythmia (produced by disconnection of the breathing capsule); and the parent's history being inconsistent with the time log on the event recorder. Such inconsistencies suggested that the symptoms reported were fabricated (Munchausen syndrome by proxy). ${ }^{9}$

Subsequent investigations included continuous recordings in hospital with the aim of capturing further events with signals additional to those on the event recorder (for example, three channels of electroencephalograms, nasal airflow, respiratory inductance plethysmography, transcutaneous or end tidal carbon dioxide). Such recordings aimed to differentiate be- tween epilepsy and a primary respiratory mechanism. In cases of suspected induced or fabricated illness, a multidisciplinary planning meeting was set up among medical and nursing staff, police, and social services (usually the child protection team). If it was considered that a parent was fabricating symptoms and manipulating recorded data a decision could be made to discuss this with the parent and family doctor. If it was considered that events could be due to suffocation covert video surveillance was considered to be an appropriate option. ${ }^{10}$

\section{HOME OXYGEN MONITORING}

All patients were considered for skin $\mathrm{po}_{2}$ monitoring at home. ${ }^{5}$ It was not undertaken in 11 of those who had been subject to suffocation, five referred before the $\mathrm{po}_{2}$ monitor was available, four patients $>1$ year with infrequent events, two for whom social problems resulted in a prolonged hospital stay, and one who died before admission. Home monitoring was discontinued when there had been no events for at least two months or two months after discontinuation of oxygen (see below).

\section{HOME OXYGEN TREATMENT}

Patients discharged on additional inspired oxygen received this by nasal cannulas (de Vilbiss). Those with baseline hypoxaemia had the flow rate determined which would maintain normal $\mathrm{SaO}_{2}$ levels in hospital ( $>95 \%$; usually $0 \cdot 1-2 \cdot 0 \mathrm{l} / \mathrm{min}$ ). Parents then observed the values of skin $\mathrm{po}_{2}$ and maintained these at home (usually $>60 \mathrm{~mm} \mathrm{Hg}$ ). Patients with recurrent events and hypoxaemic episodes on recordings received $0.5-1.01 / \mathrm{min}$. Additional inspired oxygen was discontinued only after an overnight recording performed 6-8 weeks after the last event had confirmed normal baseline and stable oxygenation.

\section{FOLLOW UP}

Patients were usually followed up for at least 6 months after the last event. Specific ethical approval was not obtained for physiological recordings, which were considered part of clinical management.

\section{Results}

PHYSIOLOGICAL RECORDINGS IN HOSPITAL

These were normal in 97 of $150(65 \%)$ patients, including 66 out of $108(61 \%)$ with recurrent and 31 out of $42(74 \%)$ with single events. Thirty five patients had abnormal hypoxaemic episodes, five had a low baseline $\mathrm{SaO}_{2}$, and 13 had both; thus $12 \%$ of the total had baseline hypoxaemia. In 28 of the $48(58 \%)$ patients with abnormal hypoxaemic episodes coincidental clinical events were observed by parents or hospital staff. Twelve of the 18 patients with clinically undetected baseline hypoxaemia were born preterm. No patient had evidence of the sleep related upper airway obstruction syndrome. ${ }^{311}$

\section{EVENT RECORDINGS AT HOME}

Of the 20 patients who had abnormal recordings in hospital and underwent home event recording, three had no further events, four had further events but without changes in the physiological signals, and 13 had events with documented hypoxaemia. In four of these hypoxaemia induced by epileptic seizure was recorded during subsequent events in hospital. ${ }^{12}$ In the nine remaining patients documented hypoxaemic episodes were consistent with a primary respiratory abnormality. ${ }^{813}$

Of the 73 patients with recurrent events and a hospital recording which was either normal or not performed, 41 subsequently underwent home event recording. In 24 there were no further clinical 
events. The following diagnoses were suggested in the remainder: no changes in physiological signals in three, skin perfusion disturbances in three, severe hypoxaemic events (confirmed to be due to epilepsy) in one, suffocation in five, and fabricated data in five.

\section{FINAL DIAGNOSES AND MANAGEMENT}

No diagnosis was established in 80 patients. In 46 no events occurred during hospital recordings and home recordings had not yet been developed; in 27 no events occurred during hospital or home recordings; and in seven events were recorded but no abnormal physiology was identified. Of those without a diagnosis, 71 underwent home $\mathrm{po}_{2}$ monitoring.

Of 77 patients with a diagnosis, two had disturbances in skin perfusion (one other patient had this, but was subsequently found to have fabricated illness); both had episodes of severe pallor and diagnosis led to reassurance for their parents.

In seven patients the data had been fabricated; confrontation was followed in all cases by cessation of symptoms and support for the parent.

Suffocation was diagnosed in 18. This was confirmed in 14 patients by covert video surveillance. ${ }^{10}$ Three patients had parental histories incompatible with event recordings and patterns on the recordings suggestive of suffocation; judicial proceedings resulted in separation of these patients from the suspected abusers, permanently in two and awaiting a decision in the third. The mother of the remaining patient confessed to abuse and the child was placed in the care of the extended family. After separation from the abuser events ceased in all patients.

Ten patients had hypoxaemic events induced by epileptic seizures. In four there was abnormal encephalographic evidence between events. In six the electroencephalogram between events was normal but recordings during events showed epileptic activity preceding the onset of prolonged apnoeic pauses or irregular breathing patterns, with falls in $\mathrm{SaO}_{2} .{ }^{12}$ In six epileptic seizures were difficult to control; in four they stopped after treatment with carbamazepine.

The 40 remaining patients had proved hypoxaemic events-that is, a fall in skin $\mathrm{po}_{2}$ or $\mathrm{SaO}_{2}$, or bothwith no evidence of epilepsy or suffocation and for which the precise mechanism remains undetermined but was probably respiratory in origin. Twenty nine of these 40 patients ( 15 with baseline hypoxaemia and 14 with recurrent hypoxaemic events) received continuous additional inspired oxygen. Events stopped in 20 , and in nine there was a reduction in their severity and frequency. Subsequent events tended to recur at the time of intercurrent infections, at which time the flow rate of oxygen was increased; none subsequently required cardiopulmonary resuscitation. Twenty seven of the 29 patients have discontinued oxygen therapy; the median duration of this treatment was 4 months (range 0.4-20.4).

Home $\mathrm{pO}_{2}$ monitoring was undertaken in 134 patients; in the 120 patients who have discontinued it lasted for a median duration of 5.5 months (range $0 \cdot 3-17 \cdot 5)$

In the 19 patients who were siblings of victims of sudden infant death syndrome, a diagnosis of suffocation was made in five, all of whom had recurrent events. In two patients with a history of single events these were considered to be of respiratory origin.

\section{SUDDEN DEATH}

Three patients died suddenly and unexpectedly at home. One occurred between referral and admission, one had recurrent cyanotic breath holding ${ }^{13}$ but the parents did not use the prescribed home $\mathrm{po}_{2}$ monitor. ${ }^{14}$ The third patient had recurrent events but none were documented. Home $\mathrm{po}_{2}$ monitoring was undertaken for 3 months and then discontinued by us. This patient died 1 month later (aged 6 months). A fourth patient died from viral pneumonia, but this was in hospital and expected.

\section{Discussion}

Physiological recordings in the hospital and home between and during apparent life threatening events have aided diagnosis and management in 77 of 157 patients. Even in the 46 patients with a single event a diagnosis was reached in nine. The provision of home recordings has provided important benefits: the validity of parental observations was objectively determined; a log of compliance with home recording was obtained; and there were fewer time constraints on its use. Although more signals can be recorded in hospital, there is a limit to how long it is appropriate to keep a patient on the ward.

We recognise that only patients reported to have received cardiopulmonary resuscitation by parents were studied. A decision by parents to initiate resuscitation is subjective and some patients will have received this without a real need, as illustrated in patients whose subsequent and similar events were due to skin perfusion changes. Conversely, there are patients with events who have not received resuscitation in whom the mechanisms responsible will be similar to those identified here.

As expected we identified a number of different mechanisms for these events. The relative proportions of the different diagnoses reached must, however, be interpreted with caution. Our unit provides a tertiary referral service and we probably see problematic cases. Of concern, a third of the patients in whom we reached a diagnosis were subject to some form of child abuse: suffocation in 18 and fabrication of the history and physiological data in seven. When we excluded patients in whom a diagnosis of suffocation had been considered before referral, 16 out of $68(24 \%)$ patients were found to be suffering abuse.

In those events in which definite hypoxaemia (falls in both $\mathrm{SaO}_{2}$ and skin $\mathrm{po}_{2}$ ) was identified and in which there was no evidence of epileptic seizure or suffocation the precise mechanism remains uncertain. The administration of additional inspired oxygen seemed to be of benefit; in 15 patients with baseline hypoxaemia this would be expected as episodic desaturation has been reported to be more severe if baseline hypoxaemia is present. ${ }^{15}$ Two thirds of those with baseline hypoxaemia had been born preterm and may have been suffering mild, clinically unapparent chronic lung disease. None of these patients, however, had been discharged from neonatal units on oxygen treatment.

In patients with episodic hypoxaemia and a normal baseline $\mathrm{SaO}_{2}$ the clinically apparent episodes were considered to represent severe manifestations of the self resolving hypoxaemic episodes that occurred on the physiological recordings. These findings have been previously described in preterm infants with cyanotic episodes. ${ }^{16}$ These episodes can be due to both apnoeic and non-apnoeic mechanisms, ${ }^{8}$ and some of the apparent benefits of additional inspired oxygen may arise through relaxation of bronchiolar or pulmonary arteriolar muscle tone, both of which may increase in response to airway hypoxia. ${ }^{17} 18 \mathrm{We}$ emphasise that the use of oxygen was uncontrolled. Our patients were manifesting potentially dangerous hypoxaemia, and we did not consider it ethically appropriate to withhold this form of treatment.

It is appropriate for infants who suffer events to be investigated for the presence of respiratory pathogens, particularly Bordetella pertussis and respiratory syncytial virus. These infections may be accompanied by clinically undetected baseline and episodic hypox- 
aemia. ${ }^{1920}$ As part of our management we advised parents to avoid, when possible, their child's exposure to respiratory infections. ${ }^{21}$

A standard electrocardiogram was recorded to exclude the long QT syndrome or other disorders of cardiac conduction. ${ }^{22} 23$ The continuous recording of electrocardiogram and from it instantaneous heart rate was particularly valuable during events. Thus epileptic seizures often began with a sustained tachycardia ${ }^{24}$ in spite of apnoeic pauses and severe hypoxaemia. The presence of profound bradycardia helped validate the occurrence of hypoxaemia when skin $\mathrm{po}_{2}$ signals were recorded without $\mathrm{SaO}_{2}$.

Although patients with events usually undergo biochemical and metabolic investigations, blood gas measurements on the arrival of such patients in the accident and emergency department are not routine. Such measurements, particularly if they show acidosis, may be valuable not only as an indicator of the severity of the event but also to help distinguish between fabricated events and suffocation in those patients in whom child abuse is the cause. ${ }^{9}$

Our management included a measurement of haemoglobin concentration and the treatment of any identified anaemia. Infants suffering these events are more likely to be anaemic, ${ }^{25}$ and its correction has been reported to reduce the frequency and severity of both apnoea of prematurity ${ }^{227}$ and cyanotic breath holding. ${ }^{28}$

The varied mechanisms highlighted in our patients apply only to the pathogenesis of apparent life threatening events. A link between these mechanisms and sudden infant death could be validated by finding prospectively a similar pathophysiology during the first event in a previously well infant. We suspect the relative proportions of the different mechanisms identified in our patients will be different quantitatively but perhaps not qualitatively from those responsible for sudden infant death.

Oren et al reported that 10 of their 76 patients died despite home monitoring of heart rate and breathing movements. ${ }^{2}$ Follow up of our patients showed a much lower rate of sudden death (two out of 156 or $1.3 \%$, leaving out the patient who died before admission). Some of our patients with suffocation or hypoxaemia induced by epilepsy might have died without a definite diagnosis and appropriate management. Even if they survive those patients undergoing suffocation are suffering unacceptable and repeated abuse. For all of these reasons the mechanisms responsible for apparent life threatening events, particularly those receiving cardiopulmonary resuscitation, must be identified and treated. Conventional management provided by paediatricians and general practitioners includes reassurance and the provision of apnoea monitoring at home: this approach may now be inappropriate.

We thank Andrew Holder, Katy Brigly, Amble, Babes in Arms, Cot Death Research, Dunhill Medical Trust, Little Ones, and the Priory Foundation for their invaluable support and Mrs Valerie Stebbens for her advice on the manuscript. Dr Poets was supported by the Deutsche Forschungsgemeinschaft, Bonn, Germany.

1 Little GA, Ballard RA, Brooks JG, Brouillette RT, Culpepper L, Gray HB, et al. National Institutes of Health consensus development conference on infantile apnea and home monitoring, Sept 29 to Oct 1, 1986. Pediatrics 1987;79:292-9.

2 Oren J, Kelly D, Shannon DC. Identification of a high risk group for sudden infant death syndrome among infants who were resuscitated for sleep apnea. Pediatrics 1986;77:495-9.

3 Abraham NG, Stebbens VA, Samuels MP, Southall DP. Investigation of cyanotic/apneic episodes and sleep-related upper airway obstruction by long-term non-invasive bedside recordings. Pediatr Pulmonol 1990;8: 259-62.

4 Poets CF, Neuber K, Noyes JP, Samuels MP, Southall DP. Event recordings of oxygenation, breathing movements and ECG in infants and young children with recurrent apparent life-threatening events (abstract). Pediatr Pulmonol 1992;14:257.

5 Poets CF, Samuels MP, Noyes JP, Jones KA, Southall DP. Home monitoring of transcutaneous oxygen tension in the early detection of hypoxaemia in infants and young children. Arch Dis Child 1991;66:676-82.

6 Stebbens VA, Poets CF, Alexander JR, Arrowsmith WA, Southall DP. Oxygen saturation and breathing patterns in infancy. I. Full term infants in Oxygen saturation and breathing patterns in infancy. 1.

7 Poets CF, Stebbens VA, Alexander JR, Arrowsmith WA, Salfield SAW, Southall DP. Arterial oxygen saturation in preterm infants at discharge from hospital and six weeks later. $₹$ Pediatrics 1992;120:447-54.

8 Poets CF, Samuels MP, Southall DP. Potential role of intrapulmonary shunting in the genesis of hypoxemic episodes in infants and young children. Pediatrics 1992;90:385-92.

9 Samuels MP, Southall DP. Munchausen syndrome by proxy. Br $\mathcal{f}$ Hosp Med 1992;47:759-62.

10 Samuels MP, McClaughlin W, Jacobson RR, Poets CF, Southall DP. Fourteen cases of imposed upper airway obstruction. Arch Dis Child 1992;67:162-70.

11 Southall DP, Croft CB, Stebbens VA, Ibrahim H, Gurney A, Buchdahl R, et al. Detection of sleep associated dysfunctional pharyngeal obstruction in infants. Eur F Ped 1989;148:353-9.

12 Southall DP, Stebbens VA, Abraham N, Abraham L. Prolonged apnoea with severe arterial hypoxaemia resulting from complex partial seizures. Dev Med Child Neurol 1987;29:784-9.

13 Southall DP, Samuels MP, Talbert DG. Recurrent cyanotic episodes with severe arterial hypoxaemia and intrapulmonary shunting: a mechanism for sudden death. Arch Dis Child 1990;65:953-61.

14 Samuels MP, Talbert DG, Southall DP. Cyanotic 'breath holding' and sudden death. Arch Dis Child 1991;66:257-8.

15 Upton CJ, Milner AD, Stokes GM. Upper airway patency during apnoea of prematurity. Arch Dis Child 1992;67:419-24.

16 Samuels MP, Poets CF, Stebbens VA, Alexander JA, Southall DP. Oxygen saturation and breathing patterns in preterm infants with cyanotic episodes. Acta Paediatr 1992;81:875-80.

17 Tay-Uyboco JS, Kwiatkowski K, Cates DB, Kavanagh L, Rigatto H. Hypoxic airway constriction in infants of very low birth weight recovering from moderate to severe bronchopulmonary dysplasia. I Pediatr 1989;115:456-9.

18 James LS, Rowe RD. The pattern of response of pulmonary and systemic arterial pressures in newborn and older infants to short periods of hypoxia. arterial pressures in new

19 Poets CF, Stebbens VA, Alexander JR, Arrowsmith WA, Salfield SAW, Southall DP. Hypoxaemia in infants with respiratory tract infections. Acta Paediatr 1992;81:536-41.

20 Southall DP, Thomas MG, Lambert HP. Severe hypoxaemia in infants with pertussis. Arch Dis Child 1988;63:598-605.

21 Southall DP, Samuels MP. Respiratory infections, hypoxemic episodes and sudden infant deaths-possible pathways in prevention? Mat Child Health 1989;14:210-7.

22 Keeton BR, Southall E, Rutter N, Anderson RH, Shinebourne EA, Southall DP. Cardiac conduction disorders in six infants with 'near miss' sudden infant deaths. BMF 1977;2:600-1.

23 Brown DC, Godman MJ. Life threatening 'epilepsy'. Arch Dis Child 1991;66: 986-7.

24 Smith PEM, Howell SIL, Owen L, Blumhardt LD. Profiles of instant heart rate during partial seizures. Electroencephalogr Clin Neurophysiol 1989;72: 207-17.

25 Poets CF, Samuels MP, Wardrop CAJ, Picton-Jones E, Southall DP. Reduced haemoglobin levels in infants presenting with apparent life-threatening vents-a retrospective investigation. Acta Paediatr 1992;81:319-21.

26 Joshi A, Gerhardt T, Shandloff P, Bancalari E. Blood transfusion effect on the respiratory pattern of preterm infants. Pediatrics 1987;80:79-84.

27 DeMaio JG, Harris MC, Deuber C, Spitzer AR. Effect of blood transfusion on apnea frequency in growing premature infants. $\mathcal{J}$ Pediatr 1989;114:1039-41.

28 Holowach J, Thurston DL. Breath-holding spells and anemia. $N$ Engl f Med 1963;268:21-3.

(Accepted 9 December 1992) 